\title{
The EMT transcription factor, Twist1, as a novel therapeutic target for pulmonary sarcomatoid carcinomas
}

\author{
TIEJU LIU ${ }^{1,2}$, XIULAN ZHAO $^{1,2}$, XU ZHENG $^{1}$, YANJUN ZHENG ${ }^{1}$, XUEYI DONG ${ }^{1,2}$, \\ NAN ZHAO ${ }^{1,2}$, SHIHAN LIAO ${ }^{1}$ and BAOCUN SUN ${ }^{1,2}$ \\ ${ }^{1}$ Department of Pathology, Tianjin Medical University, Tianjin 300070; ${ }^{2}$ Department of Pathology, \\ General Hospital of Tianjin Medical University, Tianjin 300052, P.R. China
}

Received August 30, 2019; Accepted December 12, 2019

DOI: 10.3892/ijo.2020.4972

\begin{abstract}
Pulmonary sarcomatoid carcinomas (PSCs) are a rare subtype of non-small-cell lung cancer and are typically biphasic neoplasms. No effective treatment for PSCs is currently available in clinical practice. The expression of the epithelial-mesenchymal transition (EMT) transcription factors, Twist1, Slug and Snail, as well as the EMT phenotype and vasculogenic mimicry (VM) were analysed in 41 PSC and 79 pulmonary squamous carcinoma (PSCC) samples. Compared with the PSCCs, the PSCs exhibited an EMT phenotype and VM, and they also exhibited an increased expression of the Twist1, Slug, Snail and VM markers. Twist1 expression was associated with metastasis and TNM stage. Twist1-positive patients exhibited a poorer prognosis for overall survival (OS) than those with Twist1-negative PSCs. Transforming growth factor $\beta 1$ (TGF $\beta 1$ ) was used to induce an EMT transition in a PSCC cell line. SK-MES-1 cells treated with TGF $\beta 1$ exhibited an increased expression of Twist1. The EMT phenotype, VM and increased migratory and invasive abilities were induced following TGF $\beta 1$ treatment. Importantly, in cells treated with TGF $\beta 1$, the EMT phenotype was reversed, VM marker expression was decreased, and the migratory and invasive ability of the PSCC cell line was decreased following Twist1 knockdown. Collectively, this study provides a new perspective of Twist1 in the aggressiveness of PSCs. The identification of Twist1 as an independent marker of poor prognoses may lead to the development of novel strategies for improving the treatment of patients with PSC.
\end{abstract}

Correspondence to: Professor Baocun Sun, Department of Pathology, Tianjin Medical University, 22 Qixiangtai Road, Heping, Tianjin 300070, P.R. China

E-mail: sunbaocun@aliyun.com; sunbaocun2016@hotmail.com

Key words: Twist1, epithelial-mesenchymal transition, vasculogenic mimicry, pulmonary sarcomatoid carcinomas

\section{Introduction}

Pulmonary sarcomatoid carcinomas (PSCs) are rare tumours, accounting for $<1 \%$ of all lung cancers. PSCs include spindle cell carcinoma, giant cell carcinoma, pleomorphic carcinoma, carcinosarcoma and pulmonary blastoma, with pleomorphic carcinoma being the most frequent subtype. No major changes in the terminology or diagnostic criteria have been made since the 2004 World Health Organization (WHO) classification (1). These tumours have a strong association with tobacco exposure. The clinical behaviour of PSCs is extremely aggressive, and patient prognosis is extremely poor $(2,3)$, since these tumours have a high rate of distant metastasis. The effect of conventional chemotherapy for PSCs remains controversial due to their low incidence (4); thus, progress on tumour treatments is moderate.

PSCs are typically biphasic neoplasms, including both epithelial and fusiform components (5). The fusiform components of PSCs may originate from the epithelial-mesenchymal transition (EMT) of epithelial cancer cells $(6,7)$. EMT plays a pivotal role in cancer aggressiveness, metastasis and resistance to therapy (7-10). Manzotti et al (5) provided a formal validation of EMT in the development of PSCs and functional insights into the mechanisms through which EMT occurs during PSC evolution. Previous studies $(11,12)$ have demonstrated that non-small cell lung cancer (NSCLC) cell lines treated with transforming growth factor $\beta 1$ (TGF $\beta 1)$ underwent significant EMT-related morphological changes. The cells exhibited mesenchymal features, including morphology and increased Vimentin and reduced E-Cadherin protein expression following treatment with TGF $\beta 1$. TGF $\beta 1$ induces EMT to promote lung cancer cell proliferation, invasion and metastasis $(11,12)$.

Vasculogenic mimicry (VM) represents a specific tumour blood supply pattern (13). VM provides an advantage for rapidly growing tumours that require a blood supply. Previous studies have demonstrated that VM occurs in highly invasive tumours and is associated with a high histological grade, invasion, metastasis and a short survival in patients with malignant tumours $(14,15)$. Previous studies by the authors of this study and others (16-19) have demonstrated that VM channel formation in highly aggressive human tumour cells has a close association with the EMT process. Therefore, both EMT and 
VM are synonymous with tumour plasticity, the transdifferentiation of epithelial cells to a mesenchymal phenotype, tumour aggressiveness and metastasis.

EMT transcription factors contribute to the development of resistance against cancer therapy, and they may be targeted as novel therapeutic approaches for the treatment of cancer (9). Twist1, a transcription factor of the basic helix-loop-helix class, was originally reported as a master regulator of embryonic morphogenesis. Twist1 is known to induce EMT in a variety of tumours (20-22). Previous studies by the authors have revealed that Twist1-induced EMT enhances the invasive, metastatic and VM formation abilities of hepatocellular carcinoma cells $(23,24)$. Yochum et al (25) demonstrated that Twist1 functions to suppress oncogene-induced senescence and apoptosis in multiple oncogene-driver dependent settings, including tumours with EGFR mutations. The genetic or pharmacologic inhibition of Twistl induces EGFR-mutant NSCLC cell growth inhibition and apoptosis, and it contributes to restoring tumour cell sensitivity to the chemotherapeutic agent, erlotinib.

In this study, the EMT phenotype, EMT transcription factor expression and VM were examined in 41 PSC and 79 pulmonary squamous carcinoma (PSCC) samples. The association of Twistl expression with clinicopathologic parameters was explored. The prognostic role of Twist1 in PSCs was evaluated using Cox regression and Kaplan-Meier analysis. Furthermore, PSCC cells were treated with TGF $\beta 1$ in vitro to mimic PSC cells and to demonstrate the biological behaviour of PSCs and the function of Twist1 in PSCs.

\section{Materials and methods}

Patient samples. Human lung cancer tissue collection and analysis in this study were consented to by the patients and were approved by the Ethical Committee of Tianjin Medical University. Specimens from 41 cases of PSC and 79 cases of PSCC that were fixed with formalin and paraffin-embedded from 1995 to 2010 were selected. The specimens of patients who had not undergone chemotherapy or radiotherapy prior to surgery were exclusively employed. The pathological diagnosis was reviewed by two senior pathologists based on haematoxylin and eosin-stained sections according to the 2015 WHO classification of lung tumours. All the clinicopathological parameters, including sex, age, metastasis status, histological grade, tumour size and TNM stage, were obtained from the records.

All of the patients were followed-up by a clinical interview or phone call. The overall survival (OS) time was calculated as the duration from the date of surgery to the date of death.

Immunohistochemical and histochemical double-staining methods. Tissue sections (4-5- $\mu$ m-thick) were deparaffinized and hydrated utilizing standard procedures. Immunostaining was performed using a super-sensitivity S-P IHC kit. Following immersion in $3 \% \mathrm{H}_{2} \mathrm{O}_{2}$ for 10 min to eliminate endogenous peroxidase, the sections were microwaved for antigen retrieval in Tris/EDTA pH 9.0 or sodium citrate pH 6.0 for $15 \mathrm{~min}$. After blocking in $10 \%$ goat serum for $30 \mathrm{~min}$ and incubation with primary antibodies (Twist1: 1:100, sc-15393, Santa Cruz Biotechnology; Slug: 1:150, LS-C175161, LifeSpan Biosciences; Snail: 1:100, NBP1-19529, Novus Biologicals; p63: ready to use, ZM-0406, Zhongshan Goldenbridge Biotechnology; CK5/6: ready to use, ZM-0313, Zhongshan Goldenbridge Biotechnology; CD31: ready to use, ZA-0568, Zhongshan Goldenbridge Biotechnology; Vimentin: 1:400, 2707-1, Epitomics; EPH receptor A2 (EphA2): 1:100, sc-924, Santa Cruz Biotechnology; VE-cadherin: 1:100, ab33168, Abcam; MMP2: 1:100, ab37150, Abcam; E-cadherin: 1:200, sc-8426, Santa Cruz Biotechnology) in commercialized antibody diluent at $4{ }^{\circ} \mathrm{C}$ overnight, the tissue sections were incubated with appropriate secondary antibodies (ready to use, PV-6001 and PV-6002, Zhongshan Goldenbridge Biotechnology) for $1 \mathrm{~h}$ at room temperature, and positive signals were developed in 3,3-diaminobenzidine tetrahydrochloride (DAB) solution. After counterstaining with haematoxylin for 5 min or Periodic acid-Schiff (PAS) (Zhongshan Goldenbridge Biotechnology) at room temperature, the slides were ready for microscopic examination. All sections with PAS staining were oxidized in $0.5 \%$ periodic acid solution for $5 \mathrm{~min}$, rinsed in distilled water, placed in Schiff reagent for $15 \mathrm{~min}$ and washed in tap water for $5 \mathrm{~min}$.

VM channel quantification was assessed by light microscopy (CX23, Olympus) analysis of the tumour areas. A total of 50 non-overlapping high-power fields (x400 magnification) were randomly selected per case. VM quantification was scored as follows: 0 (no VM channels were found), 1 [1 VM channel/50 high-power field (HPF)], 2 (2-4 VM channels/50 HPF), 3 (5-7 VM channels/50 HPF) and 4 (>8 VM channels/50 HPF). The cases with a score $\geq 1$ were considered VM-positive.

Staining was defined as positive for significant nuclear and cytoplasmic (Twist1, Slug Snail and p63), cytoplasmic [CK5/6, Vimentin, CD31, EphA2, VE-cadherin and matrix metalloproteinase (MMP)2] or membranous (E-cadherin) immunoreactivity in neoplastic cells. Protein expression levels were quantified according to a previous standard (26) with minor modifications. The percentage of stained cells ('P') was scored as follows: 0 (staining of $<5 \%$ of cells), 1 (5-10\% of cells), 2 (10-30\%), $3(30-50 \%)$ and 4 (>50\%). Staining intensity ('I') was graded as follows: 0 (no staining), 1 (weak staining), 2 (moderate staining) and 3 (intense staining). Samples were evaluated for both factors, i.e., ' $\mathrm{P}$ ' multiplied by ' $\mathrm{I}$ '. Ten high-power fields were randomly selected per case. The scoring of each case was a mean value of selected high-power fields. Cases with a score $>3$ were considered positive.

Western blot analysis. Cells (please see below) were lysed by using lysis buffer for western blotting (P0013, Beyotime) and loaded onto $10 \%$ sodium dodecyl sulphate-polyacrylamide gels and were then transferred onto polyvinylidene difluoride membranes (Millipore). The quantification of total protein was performed using a Pierce BCA Protein Assay kit (Thermo Fisher Scientific), and equal amounts of protein $(30 \mu \mathrm{g})$ were used for analysis. Blots were blocked with 5\% milk/TBST and incubated with primary antibodies (Twist1: 1:500, sc-15393, Santa Cruz Biotechnology; Slug: 1:1,000, 6591, Cell Signaling Technology; Snail: 1:1,000, ab53519, Abcam; Vimentin: 1:1,000, 2707-1, Epitomis; EphA2: 1:500, sc-924, Santa Cruz Biotechnology; VE-cadherin: 1:500, ab33168, Abcam; MMP2: 1:500, ab37150, Abcam; E-cadherin: 1:200, SC-8426, Santa Cruz Biotechnology; p-smad2/3: 1:500, sc-11769, Santa 
Cruz Biotechnology) at $4^{\circ} \mathrm{C}$ overnight, followed by incubation with secondary antibodies (goat anti-mouse IgG-HRP and goat anti-rabbit IgG-HRP, 1:2,000; sc-2005 and sc-2030; Santa Cruz Biotechnology) for $2 \mathrm{~h}$ at room temperature. Blots were developed using an enhanced chemiluminescence detection kit (Amersham Pharmacia Biotech). For protein loading analyses, $\beta$-actin antibody (1:1,000, P30002, Abmart) or GAPDH (1:2,000, ab9485, Abcam) was used.

Immunofluorescence. Cells cultured on glass slides were washed with PBS after discarding the medium, and they were then fixed with cold methanol at $-20^{\circ} \mathrm{C}$ for $15 \mathrm{~min}$. The cells were permeabilized with $0.1 \%$ Triton X-100 in PBS for $20 \mathrm{~min}$ and blocked with 5\% FBS in PBS at room temperature for $30 \mathrm{~min}$. The cells were then incubated with primary antibodies (E-cadherin: 1:100, sc-8426, Santa Cruz Biotechnology; Vimentin: 1:100, 2707-1, Epitomics) for $1 \mathrm{~h}$ at $37^{\circ} \mathrm{C}$. The cells were then incubated for $1 \mathrm{~h}$ with secondary antibodies conjugated to Alexa 488 (A32723, Invitrogen; Thermo Fisher Scientific) or Alexa 568 (A-11011, Invitrogen; Thermo Fisher Scientific), and then they were washed with PBS. Nuclear staining with 4',6-diamidino-2-phenylindole (DAPI) (Sigma) for $10 \mathrm{~min}$ at room temperature was then performed. Slides were viewed under a fluorescence microscope (Nikon).

Cell culture, treatment and plasmid transfection. The SK-MES-1 cells (American Type Culture Collection) were cultured in minimum essential medium (MEM) supplemented with $10 \%$ foetal bovine serum (FBS) (HyClone). The H1299 and H460 cells (Cell Resource Center, Institute of Basic Medical Sciences, Peking Union Medical College) were cultured in RPMI-1640 with $10 \%$ FBS. The cells were incubated in media with $10 \mathrm{ng} / \mathrm{ml}$ human recombinant TGF $\beta 1$ (R\&D Systems) in a humidified $5 \% \mathrm{CO}_{2}$ incubator at $37^{\circ} \mathrm{C}$ for 15 days to induce EMT.

The pGP-Twist1-shRNA plasmid was purchased from GenePharma. The target sequence [AAGCTGAGCAAG ATTCAGACC (siTwist1 nucleotides 505-525)] was used to downregulate Twist1. A non-silencing siRNA sequence (target sequence 5'-AATTCTCCGAACGTGTCACGT-3'), was used as a negative control. Plasmid vectors were transfected into the cells with polyethylenimine (PEI) (Cat. no. 23966 , PolyScience, Inc.).

Wound-healing assay. The cells were seeded in 6-well plates. When the cells reached $100 \%$ confluency, a wound was created using a $100-\mu 1$ sterile pipette tip. The wound was then photographed by using inverted phase contrast microscope (TS2, Nikon) ( $0 \mathrm{~h})$. The rate of gap closure was measured at $24 \mathrm{~h}$. To prevent apoptosis and cell detachment, 1\% FBS medium was used for $24 \mathrm{~h}$. The presence of serum in the culture medium may permit cell proliferation, influencing the results of the assay; however, the low percentage of FBS should sufficiently inhibit proliferation such that the gap closure was mainly due to cell migration. Each experiment was performed in triplicate.

Cell migration assay and invasion assay. Transwell inserts were used in 24-well plates, and cells $\left(1 \times 10^{5}\right)$ were added to the upper chamber with serum-free medium; and MEM with 10\% FBS was added to the bottom chamber. Following $24 \mathrm{~h}$ of incubation at $37^{\circ} \mathrm{C}$ and $5 \% \mathrm{CO}_{2}$, cells that remained on the upper side of the insert were removed with a cotton swab. The migratory and invasive cells were fixed with methanol and stained with crystal violet (Sigma) for $20 \mathrm{~min}$ at room temperature. Invasion assays were performed as with the migration assays, with the exception that the Transwell chambers were coated with Matrigel before the cells were seeded in the upper chamber. These cells were counted using an inverted light microscope (Nikon). Each experiment was performed in triplicate.

3D Matrigel culture. Tumour cells were mixed with Matrigel (BD Biosciences) and were seeded to allow for polymerization. The addition of regular medium was performed during the incubation at $37^{\circ} \mathrm{C}, 5 \% \mathrm{CO}_{2}$ for 1 week. Cells were incubated until tubular structures were formed and were photographed using a phase contrast microscope.

Statistical analysis. All data in this study were evaluated using SPSS17.0 software (SPSS, Inc.). The correlation between E-cadherin and Vimentin expression and VM formation was analysed using the Spearman's rank test. E-cadherin, Vimentin, VM, EphA2, VE-cadherin, MMP2, Twist1, Slug and Snail immunohistochemical staining score data were transformed into categorical data by setting up a score of $>3$ as positive and a score of $\leq 3$ as negative. Therefore, the comparison of the number of patients with positive or negative expression of these factors between PSCs and PSCCs [i.e., the comparison of positive rate (the number of patients with positive expression divided by the total number of patients with PSC or PSCC)] was performed using Chi-square test. Twist1, Slug and Snail expression in groups with different clinicopathologic parameters was analysed using the Chi-square test. Survival curves were estimated using the Kaplan-Meier method and were compared by the log rank test. Multivariate analysis of prognostic factors was tested for using Cox regression analysis. The data analysis of wound closure, invasive and migratory cell numbers was performed an using independent-samples t-test. A value of $\mathrm{P}<0.05$ was considered to indicate a statistically significant difference.

\section{Results}

PSCs display an EMT phenotype and VM formation. In this study, 41 PSC and 79 PSCC specimens were collected. Positive CK5/6 or p63 staining was found in all 79 PSCCs (data not shown). For the 41 sections of PSCs, there were 30 pleomorphic carcinomas, 7 carcinosarcomas, and 4 spindle cell carcinomas. The 30 pleomorphic carcinomas were composed of squamous cell carcinoma with positive CK5/6 or p63 expression (Fig. 1A), and they contained at least $10 \%$ spindle and/or giant cells (data not shown). This finding suggested that these pleomorphic carcinomas may originate from monoclonal malignant transformed squamous epithelium that they partially differentiate and exhibit mesenchymal characteristics. In the 7 carcinosarcomas, positive CK5/6 or p63 expression was found in 5 cases, and CK8/18 was found in 2 cases. Positive panCK staining was found in 4 spindle cell carcinomas, which demonstrated their epithelial origin (data not shown).

Compared with the PSCCs, the PSCs exhibited an EMT phenotype. E-cadherin expression was higher in the PSCC 
A

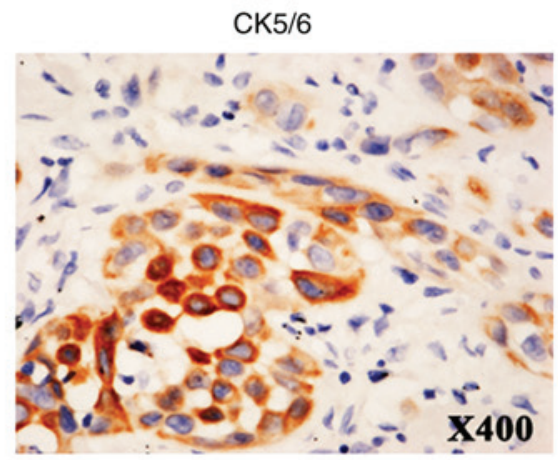

p63

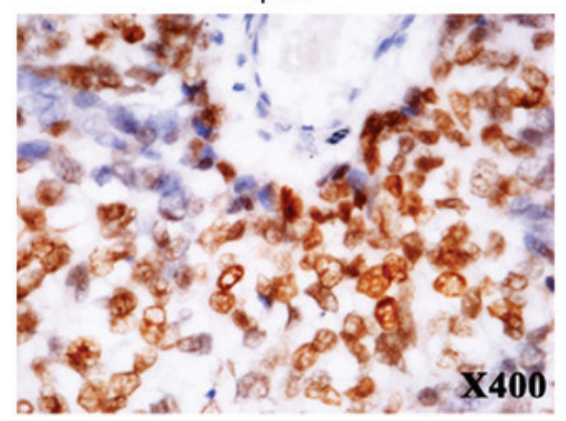

B

PSCCs

PSCS
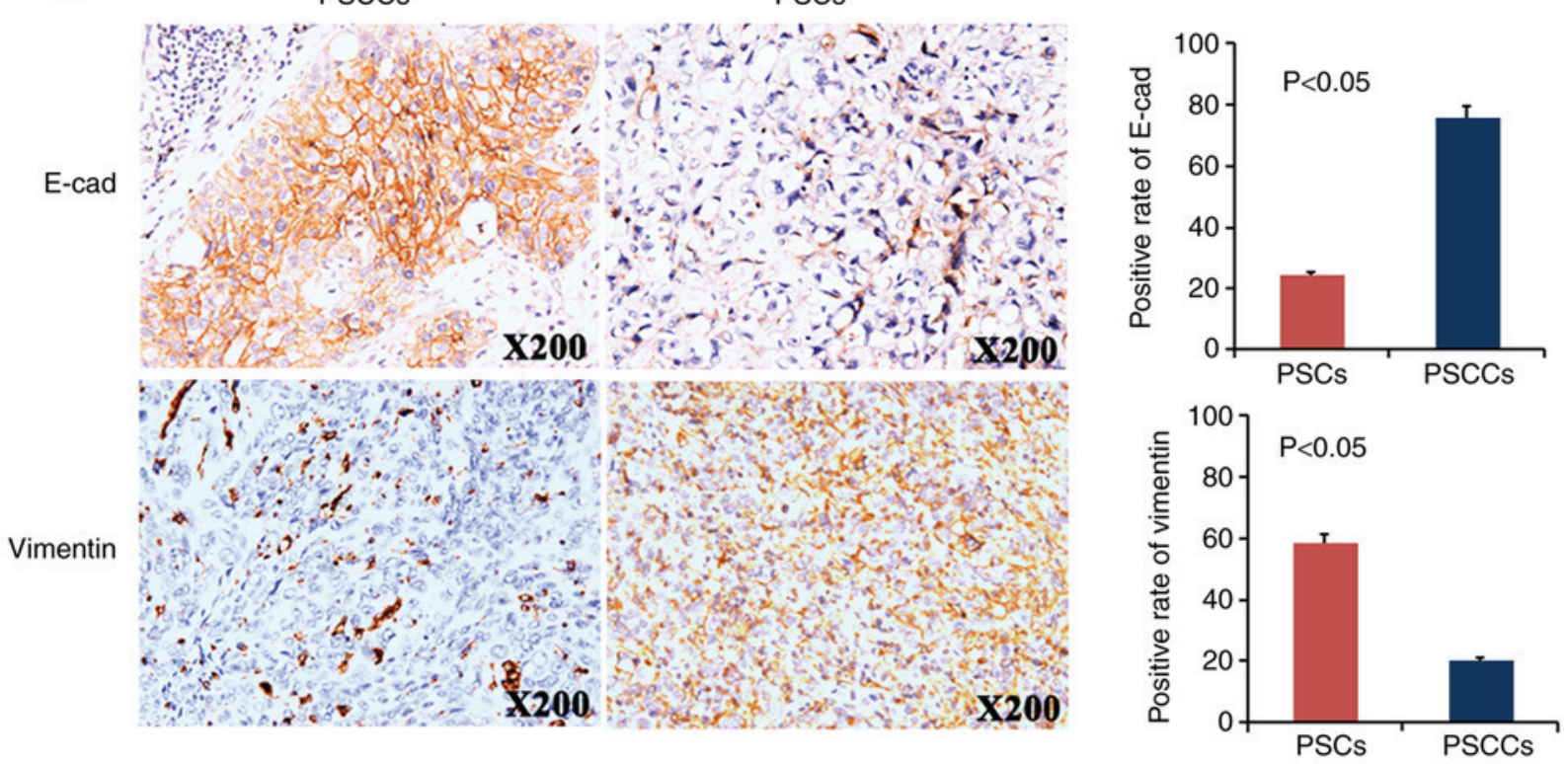

C
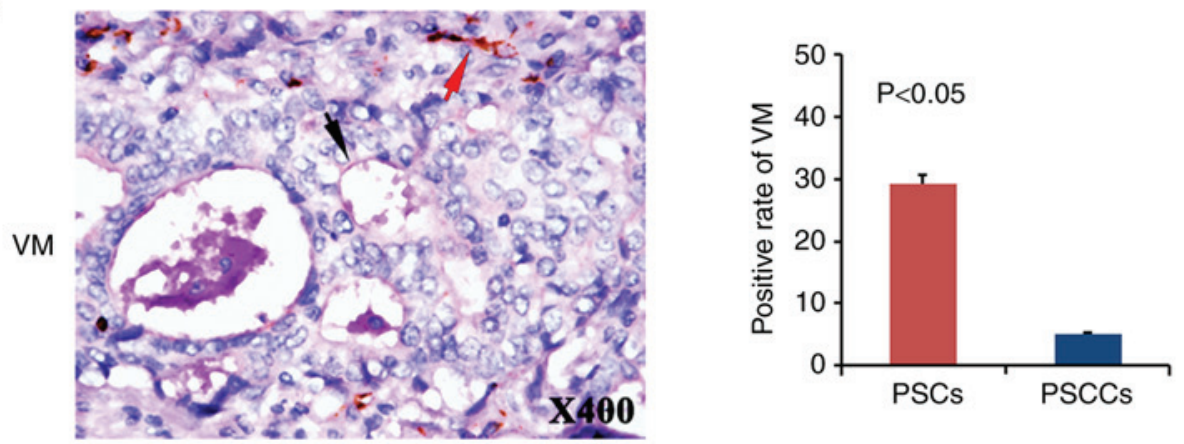

Figure 1. PSCs displayed an EMT phenotype and VM formation. (A) CK5/6 and p63 positive staining in PSCs. (B) The decreased expression of E-cadherin was more frequently detected in the PSCs group than it was in the PSCCs group. Vimentin expression was found to be higher in the PSCs group than it was in the PSCCs group. (C) VM channels (black arrow indicates VM, red arrow indicates typical CD31-positive blood vessel). The percentage rate of VM was higher in PSCs than it was in PSCCs. PSC, pulmonary sarcomatoid carcinoma; EMT, epithelial-mesenchymal transition; PSCC, pulmonary squamous carcinoma; VM, vasculogenic mimicry.

group (positive rate, $75.9 \%$ ) than it was in the PSC group (positive rate, 24.4\%). By contrast, Vimentin expression was higher in the PSC group (58.5\%) than it was in the PSCC group (20.3\%) (Fig. 1B).

Since the EMT phenotype represents tumour cell plasticity, which can contribute to VM formation, the VM channels were analysed in the PSCs and PSCCs. Using CD31/PAS double-staining (Fig. 1C), the tubular channels lined with tumour cells were considered VM formation. These tumour cells were negative for CD31 staining, demonstrating that they were not endothelial cells. The membrane-like matrix around the VM structure was positive for PAS. Necrosis and infiltration of inflammatory cells in the periphery of the channels were not observed, and red blood cells were found inside the channels. The positive VM rate differed markedly between the PSCs and PSCCs. VM was found in 12 out of 41 PSC samples $(29.3 \%)$ and in 4 out of 79 PSCC samples $(5.1 \%, \mathrm{P}<0.05$, Fig. 1C). 
A

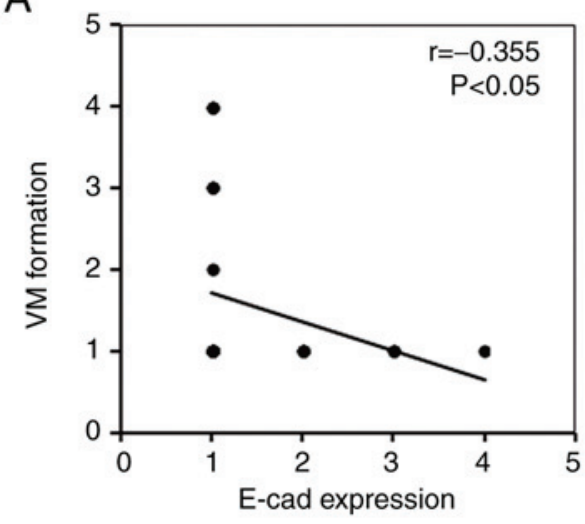

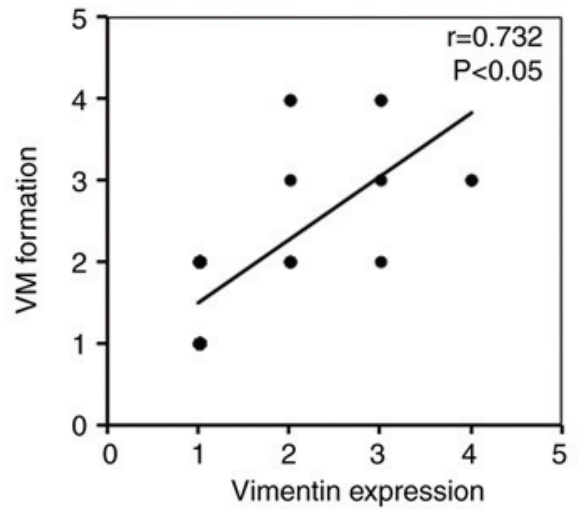

PSCCs

B
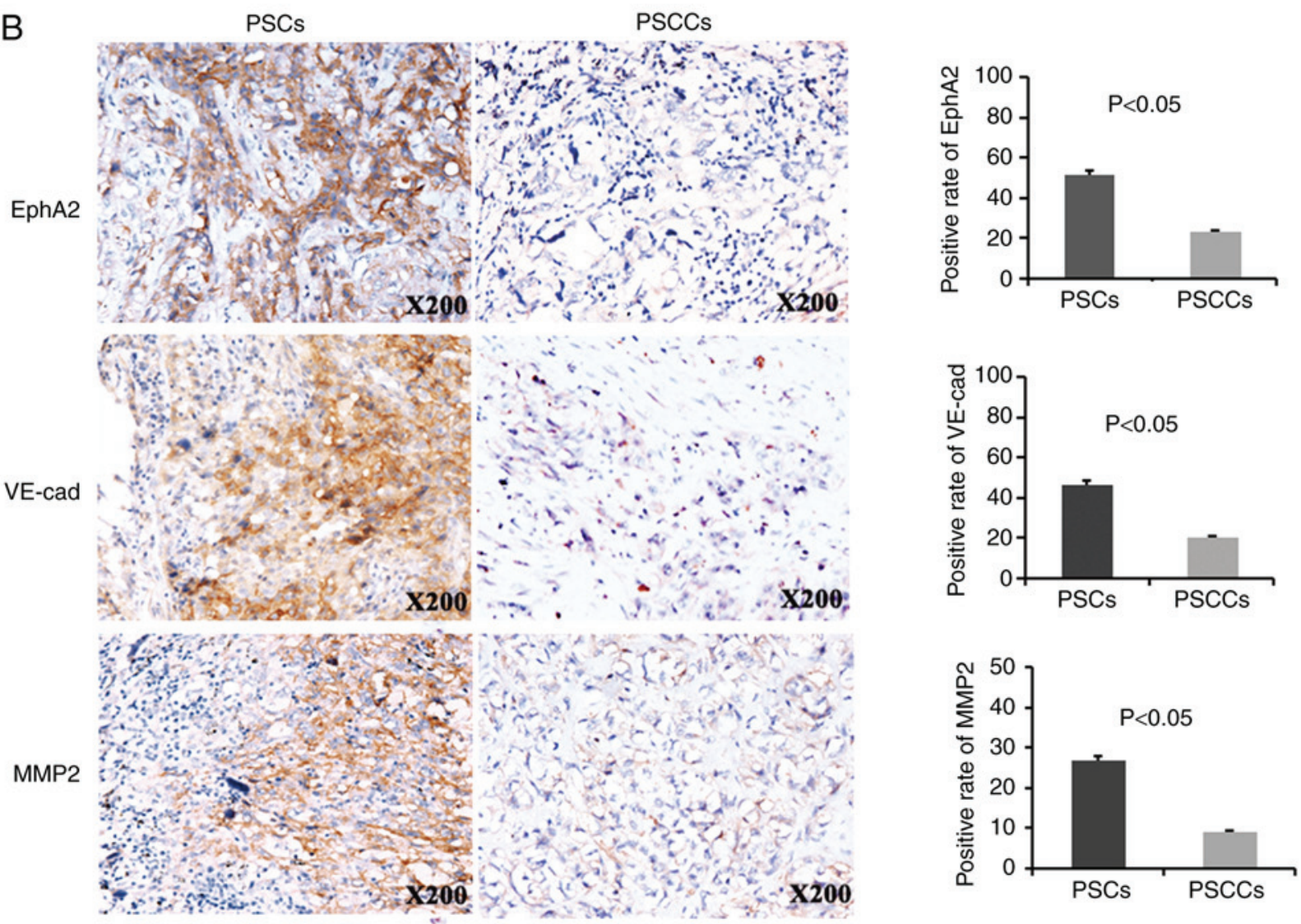

Figure 2. Expression of the VM markers, EphA2, VE-cadherin and MMP2, was increased in PSCs compared with PSCCs. (A) VM formation exhibited a negative correlation with E-cadherin expression and a positive correlation with Vimentin expression in PSCs. (B) EphA2, VE-cadherin and MMP2 positive expression in PSCs and negative expression in PSCCs. VM, vasculogenic mimicry; EphA2, EPH receptor A2; MMP2, matrix metalloproteinase 2; PSC, pulmonary sarcomatoid carcinoma; PSCC, pulmonary squamous carcinoma.

In the PSCs, VM formation exhibited a negative correlation with E-cadherin expression and a positive correlation with Vimentin expression $(\mathrm{r}=-0.355, \mathrm{P}<0.05$; $\mathrm{r}=0.732, \mathrm{P}<0.05$, respectively) (Fig. 2A). Of the $41 \mathrm{PSCs}$ analysed, $21(21 / 41,51.2 \%), 19(19 / 41,46.3 \%)$ and $11(11 / 41$, 26.8\%) were positive for EphA2, VE-cadherin and MMP2, respectively. Of the 79 PSCCs analysed, 18 (18/79, 22.8\%), $16(16 / 79,20.3 \%)$ and $7(7 / 79,8.9 \%)$ were positive for EphA2, VE-cadherin and MMP2, respectively. Therefore, the expression of the VM markers, EphA2, VE-cadherin and MMP2, was higher in the PSCs compared with the PSCCs (Fig. 2B).
Twistl expression indicates a poor survival of patients with PSC. In previous studies, the EMT regulators Twist1, Slug and Snail were found to play a role in EMT and VM in hepatocellular carcinoma and breast cancer $(19,24,27)$. Therefore, this study examined Twist1, Slug and Snail expression in PSCs and PSCCs (Fig. 3A). Correspondingly, Twist1, Slug and Snail exhibited a significantly increased expression in the PSCs (61.0, 39.0 and $34.1 \%$, respectively) over what was observed in the PSCCs (26.6, 21.5 and 17.7\%, respectively) (Fig. 3A).

The association of Twist1, Slug and Snail expression with the patient clinicopathological variables was analysed in the PSCs and PSCCs. A positive Twist1 expression, but not that 
A

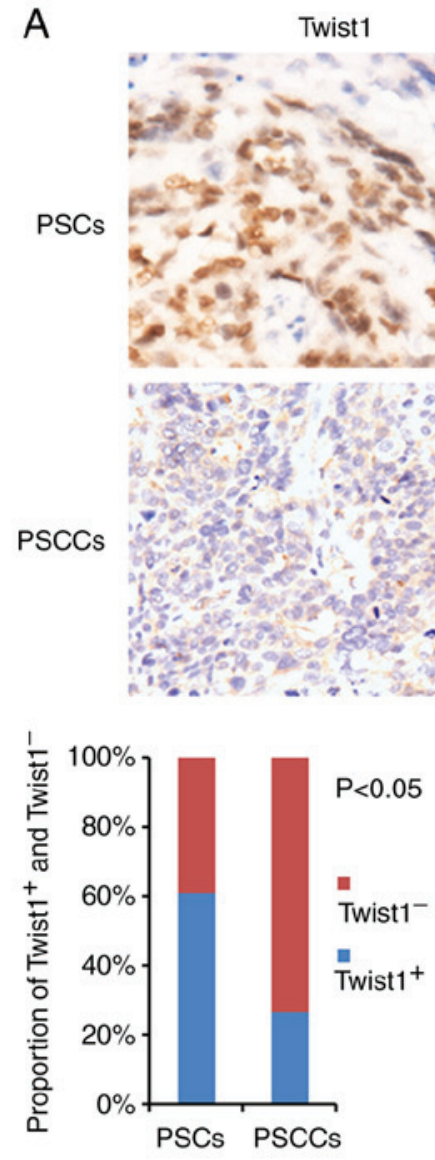

B

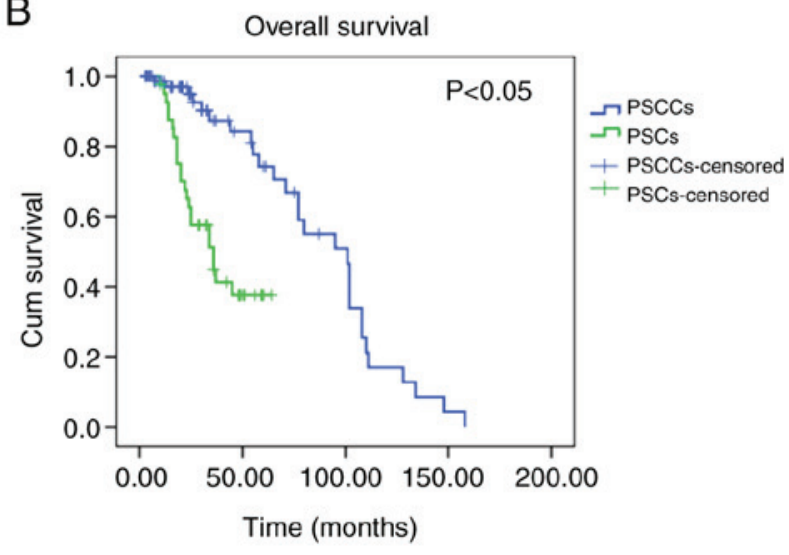

Slug
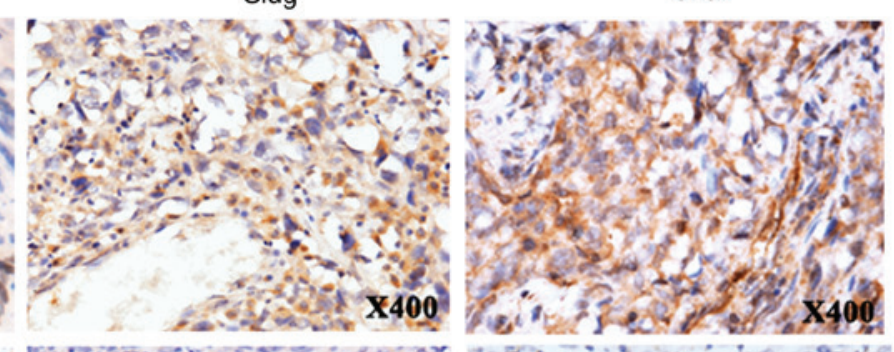

$\mathbf{X} 400$
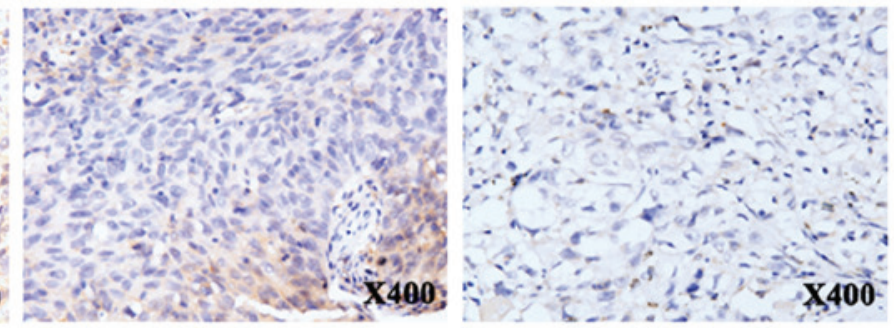
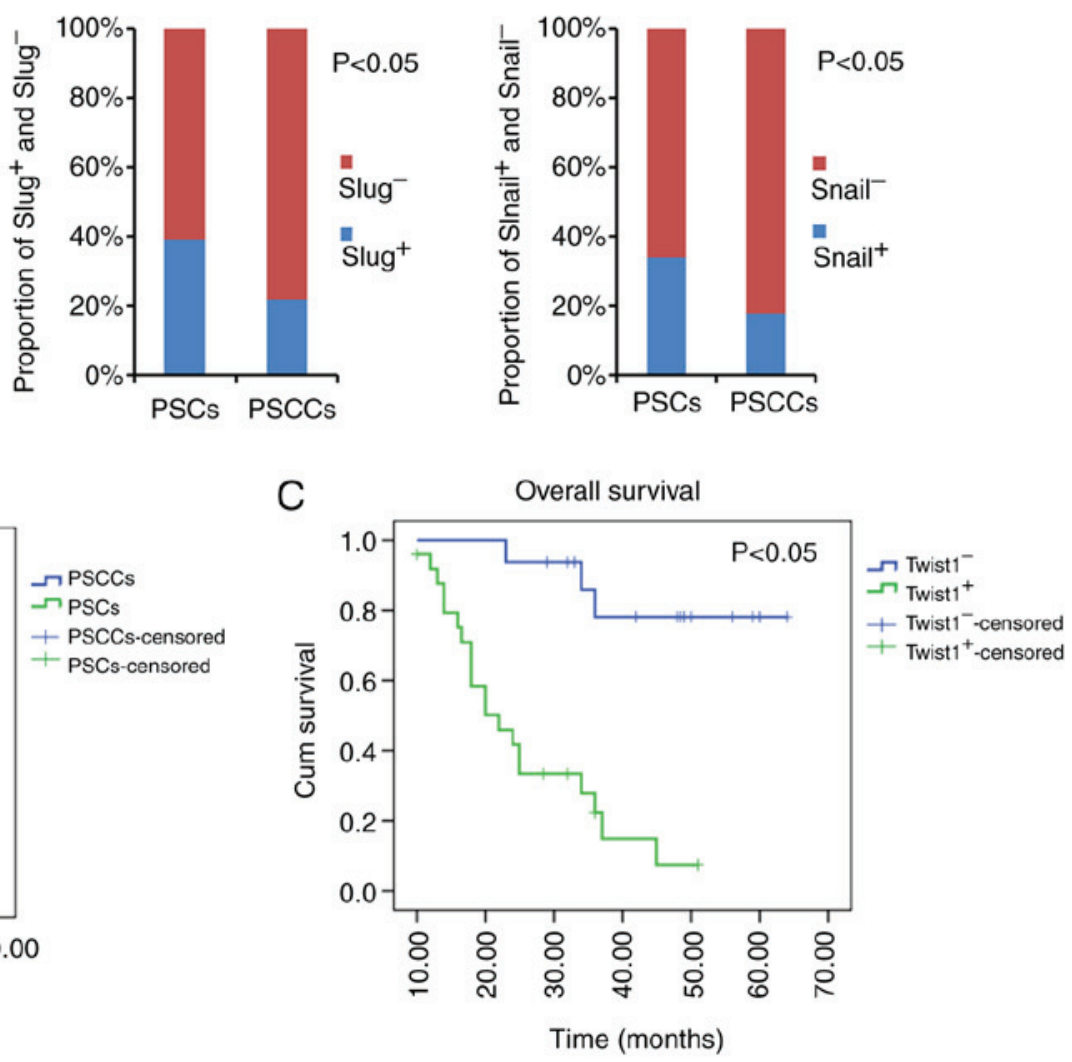

Figure 3. Twist1 positivity was an independent marker of a poor prognosis for OS in patients with PSC. (A) Twist1, Slug and Snail showed increased expression in PSCs than they did in PSCCs. (B) Patients with PSC had a worse OS than patients with PSCC. (C) Twist1-positive patients with PSC exhibited a poorer prognosis for OS than those with Twist1-negative expression. OS, overall survival; PSC, pulmonary sarcomatoid carcinoma; PSCC, pulmonary squamous carcinoma.

of Slug or Snail, was not only associated with metastasis (including lymph node metastasis, haematogenous metastasis and pleural implantation metastasis) $(\mathrm{P}<0.05)$, but also with TNM stage $(\mathrm{P}<0.05)$ in the PSCs (Table I). In the PSCCs, Snail expression, but not that of Twist1 or Slug, was associated with the histological grade $(\mathrm{P}<0.05)$ (Table II).

Kaplan-Meier survival analysis revealed that patients with PSC had a worse OS than the patients with PSCC (Fig. 3B). The mean $(95 \% \mathrm{CI})$ OS times were 39.2 (32.5-45.8) months for the patients with PSC and 88.0 (75.3-100.8) months for patients with PSCC $(\mathrm{P}<0.05)$.
Additional survival analysis revealed that the Twist1-positive patients with PSC exhibited a poorer prognosis for OS than patients with Twist1-negative expression (Fig. 3C). The mean (95\% CI) OS times were 25.7 (20.7-30.7) months for Twist1-positive patients, and 56.9 (49.7-64.1) months for Twist1-negative patients $(\mathrm{P}<0.05)$. However, there was no difference in survival time between the Slug-positive and -negative patients with PSC or between the Snail-positive and -negative patients with PSC (Fig. S1). Twist1, Slug and Snail expression did not exhibit any prognostic significance for OS in the patients with PSCC (Fig. S2). 
Table I. Twist1, Slug and Snail expression in patients with PSC with different clinicopathologic parameters.

\begin{tabular}{|c|c|c|c|c|c|c|c|c|c|}
\hline \multirow[b]{2}{*}{ Characteristic } & \multicolumn{3}{|c|}{ Twist1 } & \multicolumn{3}{|c|}{ Slug } & \multicolumn{3}{|c|}{ Snail } \\
\hline & + & - & P-value & + & - & P-value & + & - & P-value \\
\hline Sex & & & 0.072 & & & 0.160 & & & 0.153 \\
\hline Male & 15 & 5 & & 10 & 10 & & 9 & 11 & \\
\hline Female & 10 & 11 & & 6 & 15 & & 5 & 16 & \\
\hline Age, years & & & 0.087 & & & 0.288 & & & 0.228 \\
\hline$\leq 60$ & 13 & 4 & & 5 & 12 & & 4 & 13 & \\
\hline$>60$ & 12 & 12 & & 11 & 13 & & 10 & 14 & \\
\hline Metastasis & & & $0.005^{\mathrm{a}}$ & & & 0.960 & & & 1.000 \\
\hline Yes & 12 & 1 & & 5 & 8 & & 4 & 9 & \\
\hline No & 13 & 15 & & 11 & 17 & & 10 & 18 & \\
\hline Tumour size & & & 0.444 & & & 0.248 & & & 0.062 \\
\hline$\geq 5 \mathrm{~cm}$ & 11 & 9 & & 6 & 14 & & 4 & 16 & \\
\hline$<5 \mathrm{~cm}$ & 14 & 7 & & 10 & 11 & & 10 & 11 & \\
\hline Stage & & & $0.002^{\mathrm{a}}$ & & & 0.848 & & & 0.706 \\
\hline I & 4 & 11 & & 5 & 10 & & 4 & 11 & \\
\hline II & 9 & 3 & & 5 & 7 & & 5 & 7 & \\
\hline III & 12 & 2 & & 6 & 8 & & 5 & 9 & \\
\hline
\end{tabular}

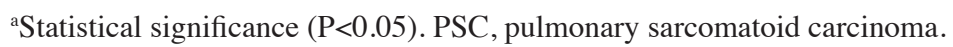

Table II. Twist1, Slug and Snail expression in groups with different clinicopathologic parameters in PSCCs.

\begin{tabular}{|c|c|c|c|c|c|c|c|c|c|}
\hline \multirow[b]{2}{*}{ Characteristic } & \multicolumn{3}{|c|}{ Twist1 } & \multicolumn{3}{|c|}{ Slug } & \multicolumn{3}{|c|}{ Snail } \\
\hline & + & - & P-value & + & - & P-value & + & - & P-value \\
\hline Sex & & & 0.300 & & & 0.729 & & & 0.186 \\
\hline Male & 16 & 37 & & 12 & 41 & & 12 & 41 & \\
\hline Female & 5 & 21 & & 5 & 21 & & 2 & 24 & \\
\hline Age, years & & & 0.793 & & & 0.621 & & & 0.425 \\
\hline$\leq 60$ & 13 & 34 & & 11 & 36 & & 7 & 40 & \\
\hline$>60$ & 8 & 24 & & 6 & 26 & & 7 & 25 & \\
\hline Metastasis & & & 0.591 & & & 0.759 & & & 0.160 \\
\hline Yes & 9 & 21 & & 7 & 23 & & 3 & 27 & \\
\hline No & 12 & 37 & & 10 & 39 & & 11 & 38 & \\
\hline Tumour size & & & 0.670 & & & 0.264 & & & 0.149 \\
\hline$\geq 5 \mathrm{~cm}$ & 9 & 28 & & 10 & 27 & & 9 & 28 & \\
\hline$<5 \mathrm{~cm}$ & 12 & 30 & & 7 & 35 & & 5 & 37 & \\
\hline Grade & & & 0.714 & & & 0.506 & & & $<0.001^{\mathrm{a}}$ \\
\hline I & 3 & 13 & & 4 & 12 & & 2 & 14 & \\
\hline II & 13 & 33 & & 11 & 35 & & 1 & 45 & \\
\hline III & 5 & 12 & & 2 & 15 & & 11 & 6 & \\
\hline Stage & & & 0.556 & & & 0.278 & & & 0.851 \\
\hline I & 6 & 23 & & 6 & 23 & & 6 & 23 & \\
\hline II & 9 & 24 & & 5 & 28 & & 5 & 28 & \\
\hline III & 6 & 11 & & 6 & 11 & & 3 & 14 & \\
\hline
\end{tabular}

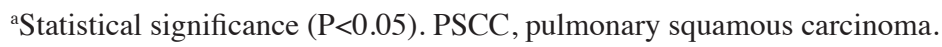



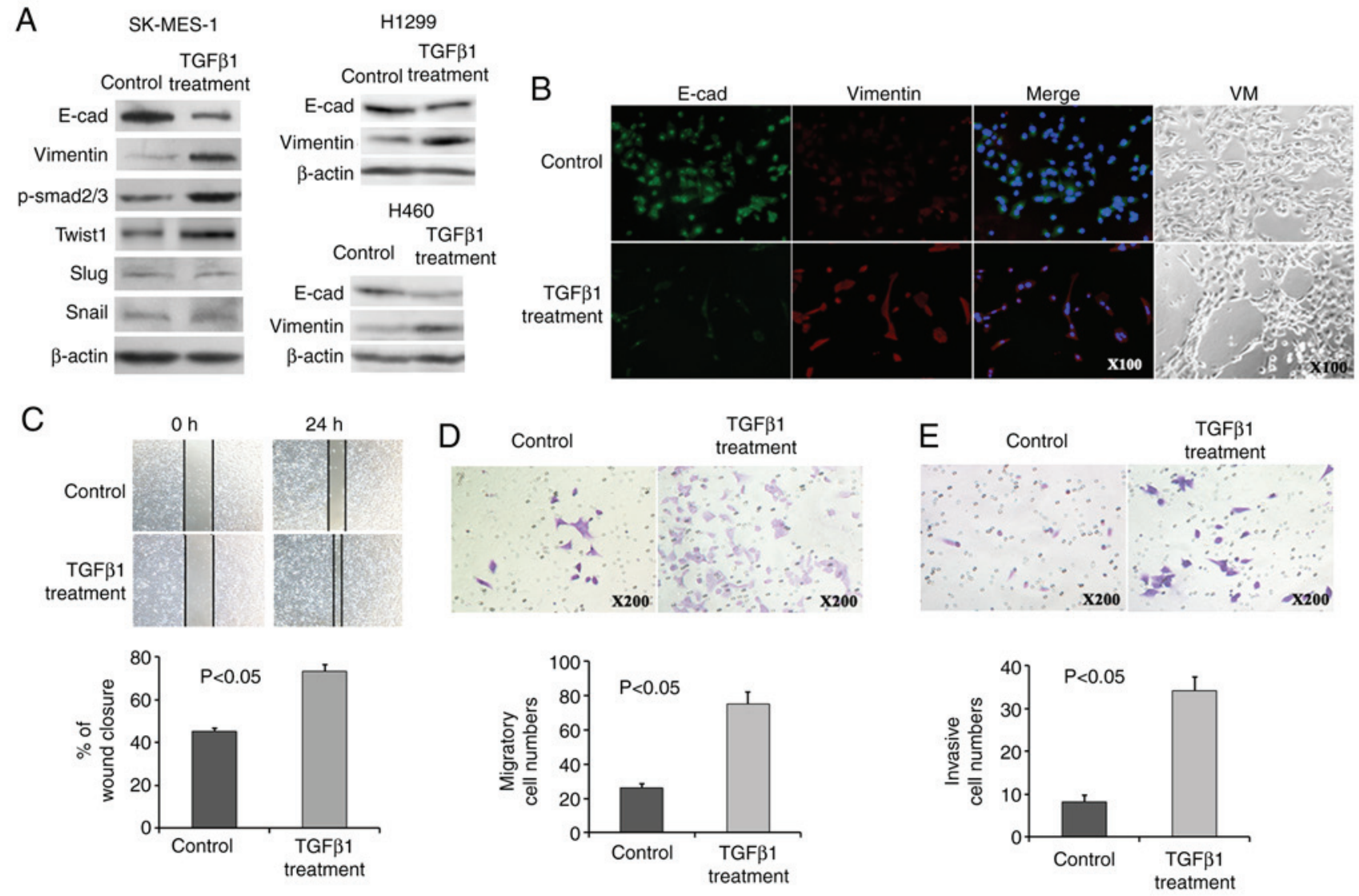

Figure 4. The PSC cell line analogue exhibited an increased Twist1 expression, EMT phenotype, VM formation and migratory and invasive ability. (A) NSCLC cells treated with TGF 31 exhibited a decreased E-cadherin and increased Vimentin expression. Twist1 and p-Smad2/3 expression was induced, while that of Slug and Snail expression was not altered following TGF $\beta 1$ treatment in SK-MES-1 cells. (B) Immunofluorescence assays revealed a decreased E-cadherin expression and an increased Vimentin expression, and 3D Matrigel culture revealed VM formation following TGF $\beta 1$ treatment. (C-E) Increased wound closure (C), migratory (D), and invasive (E) ability was observed following TGF $\beta 1$ treatment. PSC, pulmonary sarcomatoid carcinoma; EMT, epithelial-mesenchymal transition; PSCC, pulmonary squamous carcinoma; VM, vasculogenic mimicry.

In addition, multivariate Cox regression analysis was performed (Table SI), and Twist1 positivity and metastasis were identified as independent markers of a poor prognosis for OS in patients with PSC. However, TNM stage was identified as an independent marker of a poor prognosis for OS in patients with PSCC (Table SI).

EMT transition of lung cancer cell lines by TGF $\beta 1$ addition. To the best of our knowledge, no PSC-derived cell lines are currently available. Thus, TGF $\beta 1$ was used to induce the EMT transition of the NSCLC cell lines, SK-MES-1 (28), H1299 and $\mathrm{H} 460$, in order to obtain an in vitro PSC cell line analogue.

Consistently, all cells exhibited a decreased E-cadherin and increased Vimentin expression following the addition of TGF $\beta 1$, as assessed by immunofluorescence and western blot analysis (Fig. 4A and B). TGF $\beta 1$ proteins bind to receptors on the cell surface, initiating a signalling cascade that leads to phosphorylation of Smad2 and Smad3. Phosphorylated Smad then translocates to the nucleus and regulates the transcription of its target genes. Therefore, phosphorylated $\mathrm{Smad} 2 / 3$ (p-Smad2/3) was detected as a surrogate marker for TGF $\beta 1$ signalling activity, and $\mathrm{p}-\mathrm{Smad} 2 / 3$ expression exhibited a marked increase in the SK-MES-1 cells following treatment with TGF $\beta 1$ (Fig. 4A). Importantly, the expression of Twist1 exhibited a tendency towards an increased expression, although the expression of Slug and Snail did not exhibit a similar trend (Fig. 4A). These results suggest that the downstream targets of TGF $\beta 1$ signalling, as well as Twist1, may be useful markers for the evaluation of the occurrence of EMT, which converts epithelial PSCCs into PSCs with biphasic differentiation containing epithelial and mesenchymal features. In addition, the PSC cell line analogue exhibited VM formation in 3D Matrigel culture following the occurrence of EMT (Fig. 4B).

Twist1 knockdown (KD) inhibits the migration and invasion of the PSC cell line analogue. Quantitative analyses of the wound-healing assay suggested a significant difference in the speed of wound healing between the PSC cell line analogue and control SK-MES-1 cells. The PSC cell line analogue displayed a faster speed of wound healing (Fig. 4C). An increased migratory and invasive ability following treatment with TGF $\beta 1$ was observed in the PSC cell line analogue by Transwell assays (Fig. 4D and E). Twist1 downregulation in SK-MES-1 cells under standard conditions or TGF $\beta 1$ treatment was observed following transfection with shTwist1 vector (Figs. 5A and S3). Importantly, the EMT phenotype was reversed (Fig. 5A), VM marker expression was decreased (Fig. 5A), the migratory and invasive abilities were decreased (Fig. 5B), and wound closure (Fig. 5C) and VM formation (Fig. 5D) were also decreased in the PSC cell line analogue following Twistl knockdown. 

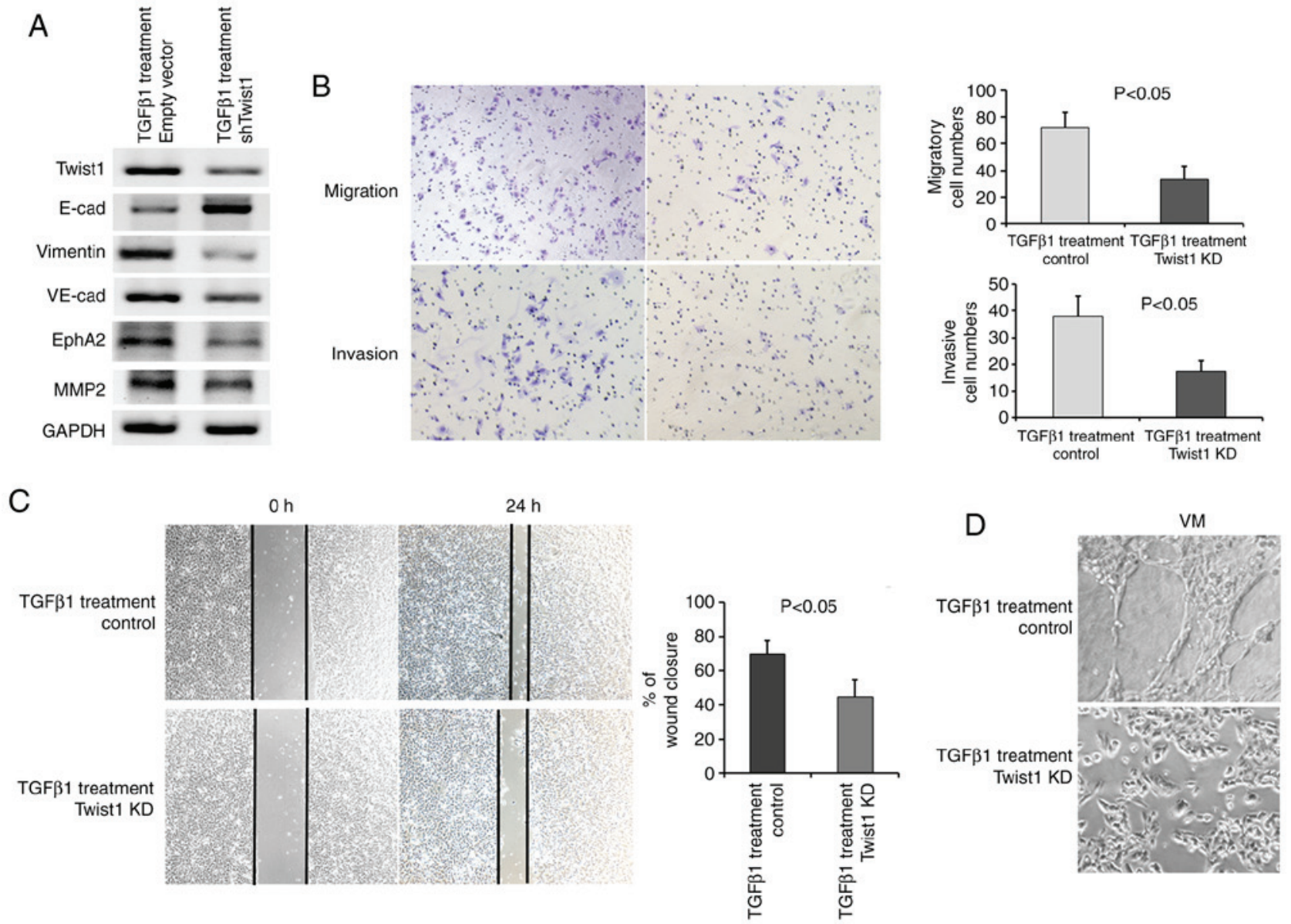

Figure 5. Twist1 knockdown (KD) inhibits the migration and invasion of the PSC cell line analogue. (A) The EMT phenotype was reversed, and VM marker expression was decreased following Twist1 KD. (B) The migratory and invasive ability of the PSC cell line analogue was decreased following Twist1 KD Decreased wound closure (C) and VM formation (D) ability was observed following Twist1 KD. EMT, epithelial-mesenchymal transition; VM, vasculogenic mimicry.

\section{Discussion}

NSCLC with spindle and/or giant cells or sarcomas that contain heterologous elements (rhabdomyosarcoma, chondrosarcoma, and osteosarcoma) are unified under the umbrella term sarcomatoid carcinoma. Molecular evidence indicates that these tumours are essentially carcinomas with varying degrees of divergent differentiation (supporting tumour metaplasia, rather than the collision 'polyclone hypothesis') (29-31). In pulmonary sarcomatoid carcinoma, the sarcomatous-like and carcinomatous components have the same molecular pedigree and are composed of the same pattern of acquired allelic absence (30), p53 mutations and X chromosome inactivation (31). In this study, the expression of CK5/6 or p63 was observed in both carcinomatous and spindled components of the sarcomatoid carcinoma, indicating that sarcomatoid carcinoma may be histogenetically converted from lung squamous cell carcinoma. Demonstrating the gene expression differences existing between PSCs and PSCCs should aid in the understanding of the mechanisms through which this conversion occurs, providing new insight into the biology of PSCs and paving the way to the definition of novel therapies.

As a transcription factor, Twist 1 can exert multiple biological effects through various downstream pathways by regulating the expression of target genes. The most critical pathological function of Twist1 in cancer is facilitating tumour invasion and metastasis by promoting EMT. EMT is a cellular plasticity process (32), which involves the loss of epithelial characteristics by epithelial cells, such as decreased cell-cell contact and the downregulation of E-cadherin, with the simultaneous acquisition of mesenchymal properties, including a spindle-like shape, increased cell motility, and the upregulation of mesenchymal markers such, as vimentin. Twist1 interacts with several components of the $\mathrm{Mi} 2 /$ nucleosome remodelling and deacetylase (Mi2/NuRD) complex (MTA2, RbAp46, Mi2, HDAC2) and recruits the factors to the proximal regions of the E-cadherin promoter to downregulate promoter activity and repress E-cadherin gene expression (33). As the downstream target of Twist1, in this study, the reduced expression of E-cadherin and the increased expression of vimentin were more frequently detected in the PSC group than the PSCC group, and they were more frequent in SK-MES-1 cells treated with TGF $\beta 1$ than in the control cells, suggesting that Twist1-induced E-cadherin repression and the EMT phenotype may be characteristics of PSCs.

The authors previously demonstrated that tumour cells with EMT characteristics can form VM, and the occurrence of both EMT and VM indicates that tumour cells harbour high plasticity $(19,24)$. In this study, there was a significant 
difference between the positive rate of VM in PSCs and PSCCs, which is consistent with the occurrence of EMT in PSCs. The tumour cells of the VM channel wall can fall off, flow into the blood and arrive at other organs to grow as a metastatic tumour. This may explain the shorter survival period observed in patients with PSC with a higher VM formation ability compared to that of patients with PSCC. In the present study, it was also demonstrated that the expression of the VM markers, EphA2, VE-cadherin and MMP2, was increased in PSCs. Remodelling of the extracellular matrix is one of the factors that governs VM channel formation, and MMP2, which can degrade various extracellular matrix proteins and facilitate tumour invasion and metastasis, is positively correlated with VM formation (34). VE-cadherin and EphA2 were also found to be co-localized in cell-cell adhesion junctions both in vitro and in vivo. It has been previously demonstrated that EphA2 and VE-cadherin interact directly and/or indirectly during VM $(35,36)$. Previous research has shown that EphA2 is a factor upstream of phosphatidylinositol 3-kinase (PI3K) and that phosphorylated EphA2 can activate PI3K and then regulate the expression of MMP-2 (37). An increased EphA2, VE-cadherin and MMP2 expression are hallmarks of VM that were more commonly present in PSCs than they were in PSCCs in this study, indicating that PSCs develop a more malignant phenotype.

To demonstrate the role of EMT in the occurrence of PSC in vitro, NSCLC cells were used and were treated with TGF $\beta 1$ to mimic PSC cells, since TGF $\beta 1$ is a well-known EMT inducer. All NSCLC cells exhibited a decreased E-cadherin and an increased vimentin expression following the addition of TGF $\beta 1$. The cells undergoing EMT cells exhibited an increased VE-cadherin, MMP2 and EphA2 expression and VM formation, suggesting that these cells may possess the biological characteristics of PSCs. The migratory and invasive ability was elevated in these cells, suggesting aggressive biological behaviour in the PSC cell line analogue. Importantly, these cells exhibited an increased Twist1 expression, and Twist1 knockdown reversed the EMT phenotype, reduced the migratory and invasive ability and the expression of VM markers. In addition, in this study, the expression of Twist1, Slug and Snail was found to be higher in the PSC group than in the PSCC group. It has been reported that Twist1, Slug and Snail can stimulate carcinoma metastasis by mediating E-cadherin repression $(19,38,39)$. Twist 1 had been found not only to function in EMT, but also to function in VM in previous studies by our group and others $(24,38)$. VE-cadherin expression is upregulated following the upregulation of Twist1 expression in the 3D Matrigel culture system (24). Of note, in this study, only Twist1 expression, not Slug or Snail, was associated with metastasis and TNM stage in patients with PSC, suggesting an important role for Twist1 in PSC metastasis by promoting and maintaining the EMT phenotype and VM formation.

Consistently, it was found that patients with PSC with Twist1-positive expression exhibited a poorer OS than Twist1-negative patients, as indicated by Kaplan-Meier analyses. There was no difference in survival time between Slug-positive and -negative or between Snail-positive and -negative PSCs. Cox multivariate analysis demonstrated that a Twist1-positive expression was an independent prognostic factor for OS in patients with PSC. These results indicated that Twist1-positive expression predicted a worse survival and may serve as the key molecular prognostic indicator for PSCs. Mechanistically, Twist1 expression in PSCs promoted tumour cell plasticity, which contributed to the EMT phenotype through the suppression of E-cadherin and the upregulation of Vimentin, and it contributed to VM formation by the upregulation of VE-cadherin; thus, Twist1 plays a role in the aggressive behaviour of PSCs. The association between Twist1-positive expression and poor survival suggests a feasible therapeutic strategy for targeting Twist1 in PSCs.

To the best of our knowledge, this study is the first report on the expression of Twist1, which is closely associated with tumour cell plasticity, EMT and VM, and may regulate the molecular mechanisms of aggressiveness in PSCs. Therefore, the findings of this study may prove to be useful in the identification of novel therapeutic targets for the inhibition of PSC angiogenesis and metastasis.

\section{Acknowledgements}

Not applicable.

\section{Funding}

This study was partly supported by a grant from The National Natural Science Foundation of China (no. 81572872 to XiZ and no. 81672870 to TL), and the Key project of the National Natural Science Foundation of China (no. 81230050 to BS).

\section{Availability of data and materials}

The datasets and data used and/or analysed during the current study are available from the corresponding author on reasonable request.

\section{Authors' contributions}

BS, TL, XiZ, XuZ and YZ conceived and carried out experiments. TL and $\mathrm{XuZ}$ conceived the experiments and analysed the data. XuZ, XiZ, YZ, XD, NZ and SL carried out immunochemistry and cell culture experiments. All authors were involved in the writing of the manuscript and gave the final approval of the submitted and published versions.

\section{Ethics approval and consent to participate}

Tissue collection and analysis in this study were approved by the Ethics Committee of Tianjin Medical University, China. Written consent had been signed by all patients.

\section{Patient consent for publication}

Not applicable.

\section{Competing interests}

The authors declare that they have no competing interests. 


\section{References}

1. Mengoli MC, Longo FR, Fraggetta F, Cavazza A, Dubini A, Alì G, Guddo F, Gilioli E, Bogina G, Nannini N, et al: The 2015 world health organization classification of lung tumors: New entities since the 2004 classification. Pathologica 110: 39-67, 2018.

2. Mignard X, Ruppert AM, Antoine M, Vasseur J, Girard N, Mazières J, Moro-Sibilot D, Fallet V, Rabbe N, Thivolet-Bejui F, et al: c-MET overexpression as a poor predictor of MET amplifications or exon 14 mutations in lung sarcomatoid carcinomas. J Thorac Oncol 13: 1962-1967, 2018.

3. Ali G, Bruno R, Poma AM, Affinito O, Monticelli A, Piaggi P, Ricciardi S, Lucchi M, Melfi F, Chella A, et al: Whole transcriptome targeted gene quantification provides new insights on pulmonary sarcomatoid carcinomas. Sci Rep 9: 3536, 2019.

4. Roesel C, Kambartel K, Kopeika U, Berzins A, Voshaar T and Krbek T: Lazarus-type tumour response to therapy with nivolumab for sarcomatoid carcinomas of the lung. Curr Oncol 26: e270-e273, 2019.

5. Manzotti G, Torricelli F, Benedetta D, Lococo F, Sancisi V, Rossi G, Piana S and Ciarrocchi A: An epithelial-to-mesenchymal transcriptional switch triggers evolution of pulmonary sarcomatoid carcinoma (PSC) and identifies dasatinib as new therapeutic option. Clin Cancer Res 25: 2348-2360, 2019.

6. Tamaki T, Shimizu T, Niki M, Shimizu M, Nishizawa T and Nomura S: Immunohistochemical analysis of NANOG expression and epithelial-mesenchymal transition in pulmonary sarcomatoid carcinoma. Oncol Lett 13: 3695-3702, 2017.

7. Aiello NM and Kang Y: Context-dependent EMT programs in cancer metastasis. J Exp Med 216: 1016-1026, 2019.

8. Campbell K: Contribution of epithelial-mesenchymal transitions to organogenesis and cancer metastasis. Curr Opin Cell Biol 55: 30-35, 2018.

9. van Staalduinen J, Baker D, Ten Dijke P and van Dam H: Epithelial-mesenchymal-transition-inducing transcription factors: New targets for tackling chemoresistance in cancer? Oncogene 37: 6195-6211, 2018

10. Kalluri R: EMT: When epithelial cells decide to become mesenchymal-like cells. J Clin Invest 119: 1417-1419, 2009.

11. Duan L, Ye L, Zhuang L, Zou X, Liu S, Zhang Y, Zhang L, Jin C and Huang Y: VEGFC/VEGFR3 axis mediates TGF 31 -induced epithelial-to-mesenchymal transition in non-small cell lung cancer cells. PLoS One 13: e0200452, 2018.

12. Zhang F, Li T, Han L, Qin P, Wu Z, Xu B, Gao Q and Song Y: TGF 1 1-induced down-regulation of microRNA-138 contributes to epithelial-mesenchymal transition in primary lung cancer cells. Biochem Biophys Res Commun 496: 1169-1175, 2018.

13. Delgado-Bellido D, Serrano-Saenz S, Fernández-Cortés M and Oliver FJ: Vasculogenic mimicry signaling revisited: Focus on non-vascular VE-cadherin. Mol Cancer 16: 65, 2017.

14. Guo Q, Yuan Y, Jin Z, Xu T, Gao Y, Wei H, Li C, Hou W and Hua B: Association between tumor vasculogenic mimicry and the poor prognosis of gastric cancer in China: An updated systematic review and meta-analysis. Biomed Res Int 2016: 2408645, 2016.

15. Qiao L, Liang N, Zhang J, Xie J, Liu F, Xu D, Yu X and Tian Y: Advanced research on vasculogenic mimicry in cancer. J Cell Mol Med 19: 315-326, 2015.

16. Wang HF, Wang SS, Zheng M, Dai LL, Wang K, Gao XL, Cao MX, Yu XH, Pang X, Zhang M, et al: Hypoxia promotes vasculogenic mimicry formation by vascular endothelial growth factor A mediating epithelial-mesenchymal transition in salivary adenoid cystic carcinoma. Cell Prolif 52: e12600, 2019.

17. Ou H, Chen Z, Xiang L, Fang Y, Xu Y, Liu Q, Hu Z, Li X, Huang Y and Yang D: Frizzled 2-induced epithelial-mesenchymal transition correlates with vasculogenic mimicry, stemness, and Hippo signaling in hepatocellular carcinoma. Cancer Sci 110: $1169-1182,2019$

18. Liu T, Sun B, Zhao X, Li Y, Zhao X, Liu Y, Yao Z, Gu Q, Dong X, Shao B, et al: USP44+ cancer stem cell subclones contribute to breast cancer aggressiveness by promoting vasculogenic mimicry. Mol Cancer Ther 14: 2121-2131, 2015.

19. Sun D, Sun B, Liu T, Zhao X, Che N, Gu Q, Dong X, Yao Z, Li R, $\mathrm{Li}$ J, et al: Slug promoted vasculogenic mimicry in hepatocellular carcinoma. J Cell Mol Med 17: 1038-1047, 2013.

20. Ding X, Li F and Zhang L: Knockdown of delta-like 3 restricts lipopolysaccharide-induced inflammation, migration and invasion of A2058 melanoma cells via blocking Twist1-mediated epithelial-mesenchymal transition. Life Sci 226: 149-155, 2019.
21. Ren H, Du P, Ge Z, Jin Y, Ding D, Liu X and Zou Q: TWIST1 and BMI1 in cancer metastasis and chemoresistance. J Cancer 7: 1074-1080, 2016.

22. Zhu QQ, Ma C, Wang Q, Song Y and Lv T: The role of TWIST1 in epithelial-mesenchymal transition and cancers. Tumour Biol 37: 185-197, 2016.

23. Sun T, Sun BC, Zhao XL, Zhao N, Dong XY, Che N, Yao Z, Ma YM, Gu Q, Zong WK and Liu ZY: Promotion of tumor cell metastasis and vasculogenic mimicry by way of transcription coactivation by Bcl-2 and Twist1: A study of hepatocellular carcinoma. Hepatology 54: 1690-1706, 2011.

24. Sun T, Zhao N, Zhao XL, Gu Q, Zhang SW, Che N, Wang XH, Du J, Liu YX and Sun BC: Expression and functional significance of Twist1 in hepatocellular carcinoma: Its role in vasculogenic mimicry. Hepatology 51: 545-556, 2010

25. Yochum ZA, Cades J, Wang H, Chatterjee S, Simons BW, O'Brien JP, Khetarpal SK, Lemtiri-Chlieh G, Myers KV, Huang EH, et al: Targeting the EMT transcription factor TWIST1 overcomes resistance to EGFR inhibitors in EGFR-mutant non-small-cell lung cancer. Oncogene 38: 656-670, 2019.

26. Sun H, Liu T, Zhu D, Dong X, Liu F, Liang X, Chen C, Shao B, Wang $M$ and Wang Y: HnRNPM and CD44s expression affects tumor aggressiveness and predicts poor prognosis in breast cancer with axillary lymph node metastases. Genes Chromosomes Cancer 56: 598-607, 2017.

27. Wang Y, Sun H, Zhang D, Fan D, Zhang Y, Dong X, Liu S, Yang Z, Ni C, Li Y, et al: TP53INP1 inhibits hypoxia-induced vasculogenic mimicry formation via the ROS/snail signalling axis in breast cancer. J Cell Mol Med 22: 3475-3488, 2018.

28. Zhang H, Chen R, Yang S, Liu W, Li K, Zhang H, Zhu X and Chen B: Lobaplatin for the treatment of SK-MES-1 lung squamous cell line in vitro and in vivo. OncoTargets Ther 9: 4215-4224, 2016.

29. Franks TJ and Galvin JR: Sarcomatoid carcinoma of the lung: Histologic criteria and common lesions in the differential diagnosis. Arch Pathol Lab Med 134: 49-54, 2010.

30. Dacic S, Finkelstein SD, Sasatomi E, Swalsky PA and Yousem SA: Molecular pathogenesis of pulmonary carcinosarcoma as determined by microdissection-based allelotyping. Am J Surg Pathol 26: 510-516, 2002.

31. Holst VA, Finkelstein S, Colby TV, Myers JL and Yousem SA: p53 and K-ras mutational genotyping in pulmonary carcinosarcoma, spindle cell carcinoma, and pulmonary blastoma: Implications for histogenesis. Am J Surg Pathol 21: 801-811, 1997.

32. Chaffer CL, San Juan BP, Lim E and Weinberg RA: EMT, cell plasticity and metastasis. Cancer Metastasis Rev 35: 645-654, 2016.

33. Zhao Z, Rahman MA, Chen ZG and Shin DM: Multiple biological functions of Twist1 in various cancers. Oncotarget 8: 20380-20393, 2017.

34. Li Y, Sun B, Zhao X, Wang X, Zhang D, Gu Q and Liu T: MMP-2 and MMP-13 affect vasculogenic mimicry formation in large cell lung cancer. J Cell Mol Med 21: 3741-3751, 2017.

35. Hess AR, Seftor EA, Gruman LM, Kinch MS, Seftor RE and Hendrix MJ: VE-cadherin regulates EphA2 in aggressive melanoma cells through a novel signaling pathway: Implications for vasculogenic mimicry. Cancer Biol Ther 5: 228-233, 2006.

36. Guo JQ, Zheng QH, Chen H, Chen L, Xu JB, Chen MY, Lu D, Wang ZH, Tong HF and Lin S: Ginsenoside Rg3 inhibition of vasculogenic mimicry in pancreatic cancer through downregulation of VEcadherin/EphA2/MMP9/MMP2 expression. Int J Oncol 45: 1065-1072, 2014.

37. Chen LX, He YJ, Zhao SZ, Wu JG, Wang JT, Zhu LM, Lin TT, Sun BC and Li XR: Inhibition of tumor growth and vasculogenic mimicry by curcumin through down-regulation of the EphA2/PI3K/MMP pathway in a murine choroidal melanoma model. Cancer Biol Ther 11: 229-235, 2011.

38. Yang J, Mani SA, Donaher JL, Ramaswamy S, Itzykson RA, Come C, Savagner P, Gitelman I, Richardson A and Weinberg RA: Twist, a master regulator of morphogenesis, plays an essential role in tumor metastasis. Cell 117: 927-939, 2004.

39. Fan XJ, Wan XB, Yang ZL, Fu XH, Huang Y, Chen DK, Song SX, Liu Q, Xiao HY, Wang L and Wang JP: Snail promotes lymph node metastasis and Twist enhances tumor deposit formation through epithelial-mesenchymal transition in colorectal cancer. Hum Pathol 44: 173-180, 2013.

This work is licensed under a Creative Commons Attribution-NonCommercial-NoDerivatives 4.0 International (CC BY-NC-ND 4.0) License. 